\title{
ESPERAS Y CUIDADOS. REFLEXIONES EN TORNO A LA GESTIÓN DEL TIEMPO DE MUJERES MIGRANTES EN DOS ESPACIOS URBANOS DE ARGENTINA
}

\author{
Waiting and care. Considerations about management of time \\ of migrant women in two urban spaces in Argentina
}

\author{
Ana Inés Mallimaci* \\ María José Magliano**
}

\begin{abstract}
Resumen. En base a un trabajo cualitativo que acompañó diversas investigaciones sobre géneros y migraciones realizadas durante los años 2012-2018, este artículo se propone analizar la incidencia de las esperas en la vida cotidiana de mujeres migrantes procedentes de Bolivia, Paraguay y Perú en dos áreas urbanas de Argentina: Gran Buenos Aires y Gran Córdoba. La hipótesis principal es que las esperas, encarnadas en las implicancias de las gestiones con diferentes agencias estatales y de la organización del cuidado familiar, deben comprenderse como una forma de cuidado. Esto permite volver inteligible las ocupaciones cotidianas que desarrollan las mujeres migrantes a la vez que visibilizar las estrategias y márgenes de acción que despliegan ante las limitaciones que les impone el contexto social.
\end{abstract}

Palabras clave: esperas; cuidados; mujeres migrantes; desigualdades; Argentina.

\begin{abstract}
Based on the findings of a qualitative research on gender and migration developed during 2012-2018, this article analyzes the incidence of waiting in the daily lives of migrant women from Bolivia, Paraguay and Peru in two urban areas of Argentina: Buenos Aires and Cordoba. The main hypothesis of this study is that waiting, embodied in the implications of the negotiations with different state agencies and the organization of family care, should be understood as a form of "care". This makes intelligible the daily occupations that migrant women develop and, at the same time, visualizes the strategies and margins of action that they deploy within the limitations imposed by the social context.
\end{abstract}

Keywords: waiting; care; migrant women; inequalities; Argentina.

\footnotetext{
Instituto de Investigaciones en Estudios de Género (IIEGE). CONICET y UNAJ. Buenos Aires, Argentina. E-mail: anamallimaci@gmail.com. Orcid: 0000-0001-9007-895X.

** Centro de Investigaciones y Estudios sobre Cultura y Sociedad (CIECS). CONICET y UNC. Córdoba, Argentina. E-mail: majomagliano@gmail.com. Orcid: 0000-0002-3028-5129.
} 


\section{Introducción}

Esperar los documentos, el turno con la Dirección Nacional de Migraciones, hacer cola para sacar el turno con los médicos de "la salita" o del hospital, esperar que sea el día del turno, la espera en la "sala de espera", esperar a ser registrada en los empleos, la inscripción en la escuela elegida, la espera ante pedidos al Estado para la obtención de algún servicio en el barrio, las colas para solucionar algún problema que pueda surgir en cualquiera de las esperas anteriores, esperar la llegada del transporte público para poder realizar los trámites o para trabajar. Las investigaciones que hemos realizado con mujeres migrantes en los últimos años reproducen estas imágenes que se materializan en una experiencia común: nuestras entrevistadas tienen "poco tiempo".

De esta manera, este artículo se propone reflexionar sobre las implicancias de las esperas en la vida de las mujeres migrantes y las dificultades que generan a la hora de poder ejercer derechos ciudadanos. Sostenemos que las poblaciones migrantes, y especialmente las mujeres, tienen un déficit temporal superior a la población nativa. El tiempo personal ("tener tiempo") es un recurso estructural desigualmente distribuido según las relaciones de clase, género y étnicas. Como veremos a lo largo de este trabajo, algunas de las características de las poblaciones migrantes en Argentina explican parte de las causas del déficit temporal que las afecta. En primer lugar, jornadas extensas de trabajo producto de las formas de segregación laboral que padecen estas poblaciones. Sus empleos se concentran en sectores precarios, inestables e informales del mercado de trabajo, lo que significa que no solo trabajan muchas horas, sino que tienen escaso poder de agencia sobre su jornada laboral. En segundo lugar, y como ya hemos señalado, los/as migrantes "esperan" mucho. Estas esperas se vinculan de modo singular con el vínculo establecido con el Estado, un actor clave para el acceso a derechos básicos. La regularización de la situación migratoria es el trámite principal por el cual deben esperar con una incidencia directa sobre las posibilidades laborales, sus derechos políticos, el acceso a planes sociales, vivienda, etc. Pero también esperan por el acceso a la salud y para figurar en los diferentes registros de las agencias estatales. Al igual de lo que ocurre con los sectores populares nativos, el modo habitual de la interacción cotidiana con las agencias estatales puede enmarcarse en el "modelo paciente" (Auyero, 2013, p. 187). En tercer lugar, el tiempo que las poblaciones migrantes ocupan en "moverse" por las ciudades, es otra de las formas en las que "gastan" su tiempo. Se espera en las paradas y estaciones la llegada de los transportes públicos que trasladan a las/os migrantes a sus trabajos y a las diferentes agencias estatales con las que tienen que interactuar, pero también se espera dentro del transporte hasta llegar a destino. La importancia de estas esperas vinculadas a la circulación se 
relaciona con el hecho de que en la Argentina existen "patrones complejos de segregación espacial” (Mezzadra, Neilson, 2016, p. 232).

En los apartados que siguen intentaremos analizar más profundamente estas dimensiones que afectan el uso del tiempo de las poblaciones migrantes y señalaremos que la "pobreza de tiempo" (Ballesteros, Freidín, Wilner, 2017, p. 64) afecta especialmente a las mujeres migrantes. La especial vinculación que tienen con las tareas de cuidados no remuneradas dentro de sus hogares (al igual que el resto de las mujeres), con los cuidados transnacionales (orientados al lugar de origen) y con la inserción preferencial en trabajos de cuidados remunerados (que suelen ser precarios, informales, lejanos y de horarios extensos) las hace particularmente vulnerables a transitar situaciones de espera.

Nuestra premisa es que las mujeres esperan por ellas y sus familias como parte integral de las tareas de cuidado que asumen de manera no remunerada enfocadas en la atención a otros/as y que sostienen los hogares cotidianamente. Definimos al cuidado de manera amplia, entendiendo como tal a todo trabajo que se realiza en pos de mantener o preservar la vida del otro y que involucra aspectos tanto materiales, como afectivos y psicológicos (Esquivel, 2010; Vega, Gutiérrez-Rodríguez, 2014; Molinier, 2005). Cuidar de otros/as no solo engloba las prácticas hacia la persona cuidada sino todo un conjunto de tareas que se requieren para garantizar el bienestar de ese otro u otra (Magliano et al., 2018). Esperar por otros/as, dependientes o no, entregar el tiempo personal, poner el cuerpo en los espacios de espera impuestos por diferentes instituciones para poder acceder a derechos básicos puede comprenderse bajo esta perspectiva como una práctica de cuidado. Un tiempo invisible, desvalorizado, no productivo, percibido como "pérdida" que ocupa gran parte de la vida cotidiana de las mujeres migrantes entrevistadas. Así, a partir de reconstruir el tiempo de espera de las mujeres migrantes en dos áreas urbanas de Argentina, la apuesta es repensar la propia noción de cuidados en el campo de los estudios migratorios.

A diferencia del análisis del "uso del tiempo" con tradición en la investigación feminista, "la espera" continúa siendo un objeto sociológico relativamente nuevo, y aún bastante invisibilizado y naturalizado, por ello este artículo se inicia con algunas consideraciones teóricas sobre la espera y continúa describiendo las especificidades de su recorrido metodológico. En tercer lugar, analizaremos las esperas que conllevan los tránsitos por los territorios donde viven y trabajan las migrantes y su impacto en la gestión de los cuidados familiares. Se revisarán las alternativas, limitadas, generadas por las mujeres migrantes para ganar algo de tiempo, especialmente aquellas relacionadas con lo que definiremos como trabajos de cuidado comunitario. El cuarto apartado se centrará en las formas de espera vinculadas a la relación cotidiana con el Estado y su centralidad en la vida de las migrantes. 


\section{La espera como objeto sociológico}

El interés actual por los temas relacionados con "las esperas" surge de una doble motivación. La primera responde a la lectura de diferentes estudios sociales publicados en los últimos años que reponen la centralidad de la espera como un problema sociológico (Pecheny, Palumbo 2017; Auyero, 2013; Scribano, 2010). En ellos, el tiempo de espera no es considerado un tiempo "perdido" o residual entre prácticas significativas, sino que se convierte en el centro del análisis social, interrogando sus sentidos y su vinculación con procesos sociales más amplios. La segunda responde a la necesidad analítica de ampliar la categoría de "trabajos de cuidado" de tal modo de volver inteligible las ocupaciones cotidianas, remuneradas y no remuneradas, de las mujeres migrantes que entrevistamos. Estas ocupaciones suponen el tiempo de espera necesario para acceder a derechos y bienes para ellas mismas o sus familias, el cual tiene un impacto directo en sus trayectorias migratorias, laborales y de cuidado.

Entendemos a las esperas como una relación social entre quienes esperan y quienes hacen esperar, ya sea alguien o un sistema. Tal como lo señalan Pecheny y Palumbo (2017), al pensar las esperas como relaciones de poder y dominación se les devuelve su carácter social demostrando que la espera no tiene nada de natural y merece ser problematizada. El tiempo de espera está desigualmente distribuido en nuestras sociedades y configura relaciones jerárquicas que subalternizan y regulan la vida de algunos colectivos, especialmente de los sectores populares, las mujeres y los/as migrantes. Las desigualdades de clase, étnicas y género se intersecan en el modo en que la espera se hace carne en la experiencia vital de las personas, no sólo porque estos sectores poseen "poco tiempo" sino porque tienen poco control sobre cómo transcurre el tiempo y, por lo tanto, poseen menos capacidad de agencia temporal (Ballesteros, Freidín, Wilmer, 2017, p. 64).

En los estudios sobre desplazamientos y migraciones la espera ha sido analizada especialmente en su vinculación con el tiempo transcurrido entre la solicitud de asilo o refugio o la regularización de la ciudadanía y su resultado. Como lo define Kobelinsky (2014), el solicitante de refugio se ve atravesado vitalmente por la espera que se constituye en el principal elemento de su situación. En Europa existen espacios especialmente diseñados para los/as "esperantes". La vida es esperar, fragmentando toda experiencia cotidiana o, mejor dicho, haciendo que la espera sea la principal experiencia de lo cotidiano. Cualquier otra actividad debe organizarse en base a esta espera y al hacerlo las personas se perciben como "atrapadas" en esta temporalidad que es, a la vez, la condición de posibilidad de la vida que desean (Kobelinsky, 2014). 
Nuestro trabajo de campo estuvo dirigido a mujeres peruanas, paraguayas y bolivianas que residen en dos áreas urbanas de Argentina: el Gran Buenos Aires (CBA) y el Gran Córdoba (GC)ํ․ En Argentina estas nacionalidades obtienen desde 2004 la "residencia temporal" cuando se solicita sin mayores condiciones (al igual que el resto de los países miembros y asociados del Mercosur). Si bien esto también supone prácticas de esperas, las consecuencias subjetivas y cotidianas no pueden asemejarse a las de quienes solicitan el asilo o refugio.

Debido a su pertenencia de clase, etnicidad y género, las esperas de nuestras interlocutoras migrantes se asemejan a las que enfrentan las mujeres nativas de los sectores populares, con quienes comparten la responsabilidad con exclusividad de la organización del cuidado familiar y de generar los vínculos con las agencias estatales. No obstante ello, el argumento de este artículo sostiene las mujeres migrantes se encuentran entre aquellas personas que esperan más que otras, pues en ellas la "pobreza de tiempo" tiene un plus que reside en las implicancias que supone la realización de los trámites migratorios, terreno eminentemente femenino, el cual insume un tiempo de espera fundamental. El resultado del trabajo de campo muestra que fueron mujeres las encargadas de gestionar los vínculos establecidos con las agencias estatales tanto para ellas como para sus familias. Así, el Estado es un actor central en sus vidas teniendo el poder de definir las formas de existencia de los migrantes, ya sea respecto a la regularidad/irregularidad del status migratorio como a las categorías de regularidad establecidas en la legislación vigente (en referencia a la residencia precaria, temporaria o permanente). Estas poblaciones, especialmente al inicio de su migración, deben destinar una parte importante de su tiempo a realizar trámites, a la vez que se ocupan del cuidado familiar no remunerado y, en la mayoría de los casos, del cuidado remunerado como inserción laboral principal. Esa "pobreza de tiempo" se nutre tanto de la escasez del recurso como de la escasa capacidad que tienen para controlar y flexibilizar la actividad laboral y "comprar" el tiempo de otros/ as para liberar tiempo personal (Ballesteros, Freidin, Wilner, 2017).

\section{Apuntes metodológicos}

En términos metodológicos, para la realización de este artículo nos apoyamos en un trabajo cualitativo llevado adelante durante el período 2012-2018 en GBA y GC con mujeres migrantes de origen boliviano, paraguayo y peruano que se dedicaban primordialmente a los trabajos de cuidado remunerados y, en menor medida, a la costura; ocupaciones donde la

\footnotetext{
1 Buenos Aires es el principal destino de estas tres corrientes migratorias. En el caso de Córdoba, los dos orígenes mayoritarios de la población migrante son Bolivia y Perú. Sin embargo, desde los últimos años se observa un crecimiento sostenido de migración paraguaya.
} 
población migrante se encuentra sobrerrepresentada². Pese a que al inicio de la investigación la cuestión de la espera no resultaba un interés principal; fue un emergente claro del trabajo de campo. Las mujeres migrantes, en sus relatos, hacían constante referencia a todo el tiempo que dedicaban diariamente a esperar, a veces con mal humor, otras con resignación. De esta manera, el material empírico hizo evidente la importancia de la espera que, en tanto investigadoras, habíamos naturalizado como actividad no significativa de la vida de las mujeres. Así, empezamos a prestar atención al tema de las esperas y su incidencia en la cotidianidad de nuestras interlocutoras.

El trabajo de campo recuperó tres técnicas de recolección de datos: las entrevistas en profundidad, las conversaciones informales y la observación participante. El desarrollo de este artículo retoma los testimonios de 35 mujeres migrantes. Las entrevistas en profundidad fueron grabadas y constaron, en algunas ocasiones, de más de un encuentro con nuestras interlocutoras. En el GBA se realizaron 19 entrevistas a mujeres migrantes ( 9 eran bolivianas, 6 peruanas y 4 paraguayas); mientras que en el GC se desarrollaron un total de 16 entrevistas ( 9 eran peruanas, 5 bolivianas y 2 paraguayas) ${ }^{3}$. Asimismo, incluiremos en el análisis conversaciones informales y 40 registros etnográficos de observación participante que hemos reunido durante las diferentes instancias del trabajo de campo. Las conversaciones informales fueron charlas que mantuvimos con las mujeres, en especial cuando las acompañamos en sus recorridos por la ciudad para ir a trabajar, al hospital, al "centro" por recreación o cumplimentar algún trámite en agencias estatales. En cuanto a la muestra, en ambos escenarios se trata de mujeres adultas, en edades laborales y que al momento de la entrevista habían residido en el país por más de un año. Mediante las distintas técnicas metodológicas aplicadas accedimos a un conjunto de información relacionada con las formas y el momento histórico de la migración a la Argentina, las trayectorias laborales en los lugares de origen y destino, los modos de organización del cuidado familiar, el tránsito por la ciudad; y los distintos vínculos que establecen con las agencias estatales.

\section{Esperas y organización familiar del cuidado}

Todas las mujeres migrantes entrevistadas son las responsables directas del cuidado, organización y limpieza de sus hogares, así como de la gestión del lazo con el hogar de origen en el caso de constituir familias transnacionales.

2 Es importante aclarar que nuestro interés no radica en la comparación de los resultados en ambos contextos, que presentan características diferentes en términos históricos y de estructura económica y poblacional, sino poner en diálogo y dar cuenta de ciertos procesos similares vinculados a la "pobreza de tiempo" de nuestras interlocutoras.

3 Los nombres de las personas que figuran en este texto han sido modificados para preservar su anonimato. 
El tiempo que disponen cotidianamente depende de la resolución de estas actividades ya sea con su presencia o en la gestión y organización "a distancia" de las diferentes actividades. La "pobreza de tiempo" de las mujeres supone la realización de estas actividades de cuidado no remunerados. Sin embargo, siendo una dimensión ya trabajada en múltiples trabajos (Mallimaci Barral, 2019; Magliano, 2013; Herrera, 2016) que reflejan los resultados de nuestras propias investigaciones, no profundizaremos sobre ella. Nos centraremos en este apartado en el tiempo invertido en circular por las ciudades y sus efectos en las formas de organización familiar y en las esperas que suponen las relaciones con el Estado.

\section{Tiempo y circulaciones}

En los comienzos del trabajo de campo, una de las cuestiones que recurrentemente emergían era la fuerte disociación, en términos espaciales, entre los lugares de trabajo de las mujeres y los lugares donde vivían. Al residir en las periferias urbanas, las distancias se materializan en dificultades concretas de organización y gestión de la vida cotidiana. El hecho de tener que tomarse distintos medios de transporte público para cumplimentar la presencia en los lugares de trabajo o para realizar diferentes trámites, dificulta las tareas de cuidados no remunerado en el ámbito familiar sostenido con exclusividad por las mujeres.

Los procesos de segregación espacial que enfrenta un amplio conjunto de la población migrante se expresan en la constitución de fronteras urbanas (Mera, Marcos, 2015) que excluyen a la población migrante de algunas zonas, y los circunscriben a otras donde priman condiciones de vida deficitarias. En este marco, los migrantes tienen un elevado peso relativo en "las urbanizaciones populares de origen informal" (Vaccotti, 2017) a las que acceden a través de procesos de tomas de tierras -en general fiscales- ubicadas en las periferias (Magliano, Perissinotti, 2020).

En el caso particular de quienes se dedican al empleo doméstico, principal ocupación de nuestras interlocutoras, los largos recorridos diarios que deben realizar para llegar a sus trabajos están directamente relacionados con la modalidad en que se organiza la localización de los diferentes estratos sociales en la ciudad: la distancia recorrida por las trabajadoras domésticas es aquella que separa los lugares donde se encuentran los hogares que demandan trabajadoras domésticas y los hogares donde estas trabajadoras viven. Al tiempo de espera y los costos económicos (no siempre contemplados en los ingresos salariales), se le suma el cansancio que suponen los desplazamientos. Mónica, una migrante oriunda de Trujillo (Perú) que trabajaba como empleada doméstica en el barrio Urca de la ciudad de Córdoba, no solo ponía en palabras ese cansancio, sino que lo revelaba en sus gestos y en su tono de 
voz. En una entrevista que mantuvimos en diciembre de 2012, comentó que se tomaba dos colectivos para llegar a su lugar de trabajo "porque uno que va desde acá no entra a Urca, son dos a la ida y dos a la vuelta. Y cuando llego sigo trabajando acá porque tenemos un pequeño kiosco en casa" (Mónica, peruana, 45 años, 2012, Córdoba). En esa misma oportunidad, y ante la pregunta respecto a cómo se sentía al final del día, no dudó en responder: "es muy sacrificado" (Mónica, peruana, 45 años, 2012, Córdoba). También Ana, otra migrante peruana que reside en Córdoba, grafica con sus palabras las implicancias de las "esperas":

Para llegar a mí trabajo, en la zona norte, allá por Villa Allende (zona norte de Córdoba), me tenía que tomar todos los días dos colectivos y no te cuento las esperas de los colectivos en las paradas. Eran muchas horas, entre el trabajo y los viajes y el sueldo no me rendía (...). Estaba todo el día afuera y a mis hijos casi no los veía.

¿Y quién los cuidaba mientras vos trabajabas?

El más chico iba a la guardería, la que está en el otro barrio porque acá todavía no estaba la Sala Cuna y el otro a la escuela, después los cuidaba una vecina y yo le tenía que pagar. Y el sueldo no me rendía. Ahora me conviene cobrar el Salario ${ }^{4} y$ trabajar en la copa de leche acá en el barrio, no me tengo que mover y no gasto más en alguien para cuidarlos. (Ana, peruana, 42 años, Córdoba, 2018)

Como vemos, la evaluación del tiempo de espera que insumen las distancias por parte de las migrantes es señalado como un elemento central a la hora de tomar algunas decisiones en torno al trabajo y al lugar donde vivir. $\mathrm{Si}$ en ocasiones se reorienta la trayectoria laboral, como en el caso de Ana; en otros casos se decide priorizar habitar determinados espacios urbanos como una estrategia que permita ahorrar tiempo. Así pues, en el caso de la Ciudad Autónoma de Buenos Aires (CABA), algunas de las mujeres que viven en barrios urbanos relegados pero ubicados en zonas relativamente céntricas, y tienen la posibilidad de comprar algún terreno en la provincia de Buenos Aires, prefieren quedarse en sus barrios por el tiempo y el dinero que significaría movilizarse diariamente hacia sus trabajos. "Ha habido momentos en los cuales yo me tenía que tomar colectivo, tren, colectivo. Eso me pasó cuando yo conseguí un trabajo en provincia, en Villa Bosch. Vivía por Flores, entonces como que yo empezaba a trabajar a las 7 de la mañana, tenía que salir de mi casa a las 5 para llegar, alcanzar un colectivo, era muy difícil movernos", nos comentó Úrsula, una migrante boliviana que vive en la CABA.

Varias de nuestras interlocutoras que viven en Buenos Aires enfatizaron que el acceso a la vivienda es más sencillo, en términos económicos, en provincia que en capital. Sin embargo, la calidad del sistema de transporte

4 Se refiere al Salario Social Complementario. A nivel nacional, en el 2016, se aprueba la Ley de Emergencia Social que contempla la adopción de un Salario Social Complementario destinado a "complementar" el salario que los trabajadores de la economía popular reciben por sus trabajos. 
público que permite el acceso a la ciudad de las poblaciones que residen en otras localidades es uno de los aspectos más cuestionados:

Es mucho más fácil edificar y comprarse algo en provincia, es más barato, más accesible (...) Pero es un caos, en los trenes, en los colectivos, es un caos. Sí, sí. Tendría que haber más, si hubiera más servicios, mejor servicio de transportes, tendríamos menos autos en la ciudad. (Camila, paraguaya, 45 años, CABA, 2017)

Y acá, yo vine en el 2005. (...) Yo trabajaba en capital, y era un viaje, una lucha, yo por ahí viajaba así en, pisaba la puerta del tren y colgada así, entonces me dio miedo, "un día voy a terminar a orillas del tren".

¿Dónde vivías en ese tiempo?

En Villa de Mayo. Me tomaba el Belgrano, Belgrano Norte, el tren que sale de Retiro. (Adriana, paraguaya, 39 años, CABA, 2017)

La "pobreza de tiempo" que tienen estas mujeres es lo que permite explicar que una de las alternativas más requeridas sea la obtención de un trabajo dentro de los propios barrios donde viven para así sortear uno de los problemas más difíciles de resolver cuando no se cuenta con recursos suficientes, como es la organización familiar del cuidado. Así, el trabajo comunitario remunerado a través de políticas sociales implementadas por los Estados nacional y provinciales se transforma en una alternativa cada vez más requerida por las mujeres migrantes para poder ganar algo de tiempo. Por trabajo comunitario nos referimos a aquellas tareas que se realizan de manera coordinada y/o cooperativa de forma más o menos estable en el tiempo con objetivos múltiples, buscando la satisfacción de necesidades básicas de la existencia social y por tanto individual (Gutiérrez Aguilar, Salazar Lohman, 2015, p. 23).

En las periferias urbanas, el trabajo comunitario se encuentra orientado a los cuidados (guarderías, copas de leche, comedores, etc.) y, como señala Rosas (2018, p. 306), "incluye un conjunto de actividades diversas, orientadas a sostener la reproducción cotidiana de la vida". Una reproducción que se ve amenazada por constreñimientos de clase, género y étnicos que las poblaciones migrantes enfrentan y que se materializan en sus trayectorias laborales y, también, en sus derroteros espaciales. El trabajo comunitario surge, entonces, como una opción buscada por las propias mujeres, siempre en un universo acotado de posibilidades laborales, en la medida en que viene a mitigar algunas de las problemáticas más urgentes -la escasa agencia temporal y los costos que supone moverse diariamente por la ciudad, las dificultades para sostener proyectos familiares, las condiciones laborales precarias, entre otras- que moldean sus experiencias de trabajo en los lugares de destino.

Si el tiempo de espera es una de las expresiones que explica las recurrentes dificultades para conciliar el trabajo y la organización del cuidado familiar, en contextos de fuertes procesos de segregación laboral y espacial que enfrentan 
las familias migrantes; las implicancias de las esperas en sus vidas cotidianas en el marco de las responsabilidades del cuidado se manifiestan, como veremos a continuación, en las barreras presentes para ejercer ciudadanía. Con esto nos referimos a las dificultades concretas que estas mujeres encuentran a la hora de vincularse con las agencias estatales a partir de los tiempos, ritmos, exigencias que esas agencias imponen.

\section{A la espera de derechos}

Las formas de relación que se mantienen con el Estado son fundamentales en la experiencia de vida de gran parte de la población. Como señala Auyero (2013), el Estado sigue siendo un actor clave para vastos sectores de la población de ahí la importancia del análisis de los vínculos establecidos con las agencias estatales. A la espera en las filas se le suma la opacidad de la información, la falta de certeza sobre los requisitos para los diferentes trámites, la incertidumbre del tiempo que deberá esperarse y la sensación de arbitrariedad en la resolución. Se trata así de una espera incierta.

Por otra parte, la construcción del sujeto paciente requiere la aceptación de esta espera. $\mathrm{O}$, dicho de otra manera, aprender a ser "paciente". Esto es especialmente cierto para el caso de la población migrante donde el discurso moral atraviesa el vínculo con el Estado: La documentación migratoria, la salud, la educación son bienes que se "merecen" y una manera de demostrarlo es "saber esperar". En los próximos apartados nos centraremos especialmente en la interacción de las mujeres migrantes con dos áreas estatales: los trámites para la obtención de la documentación y el acceso a la salud pública que emergieron en las entrevistas como las principales demandantes del tiempo de las mujeres. Asimismo, se trata de trámites que resultan significativos para ellas dado que implican la regulación de su residencia y el acceso a la salud tanto propia como de sus familias.

\section{Ciudadanía}

Como ya hemos señalado más arriba, desde el año 2004 en Argentina quienes hayan nacido en países del Mercosur y asociados tienen derecho a una residencia legal en el país. Teniendo en cuenta la nacionalidad de nuestras entrevistadas, todas cumplen con las condiciones requeridas por la normativa vigente para acceder a una residencia temporal. Sin embargo, se trata de trámites donde la espera impera como experiencia en tanto son siempre más largos de lo que indican las normativas. Además de los problemas relativos a la información y los costos, se suma la disposición del tiempo necesario para poder transitar las esperas del "modelo paciente". El peregrinaje por las diferentes instituciones requiere de una larga espera, que puede transformarse en horas, meses e incluso años. Volverse ciudadano supone tener tiempo para 
poder esperar lo que, como hemos visto, no es cosa sencilla en las vidas de nuestras entrevistadas.

El trámite migratorio era largo, ahora es turno por internet, antes tenías que ir muy temprano, conseguir el turno y hasta que te atiendan era un día perdido. Y ahí los empleadores no son muy susceptibles, era "No, utiliza el día de tu franco y fíjate cuál es el día de tu franco para hacer eso". (Rosa, peruana, 43 años, CABA, 2016)

Ya tenía la precaria. Después de dos años volví a hacer de vuelta. Un tiempo perdí, cierto. Me faltaba no me acuerdo qué, me hicieron mal, y estuve sin retirar la precaria, por un tiempo bastante.... Creo que por un año dejé de lado el documento. No me acuerdo de que era lo que venía mal, y me renovaba de vuelta la precaria. Y después se me venció y tuve que hacer de vuelta eso porque al principio era dos años, y venías y te hacían el definitivo. Y entonces lo volví a hacer de nuevo, volví por dos años de vuelta. (Luana, paraguaya, 37 años, CABA, 2017)

Me costó sacar el documento, empezaba y no lo terminaba. Lo empecé varias veces. Es que eran muchos trámites, como los antecedentes, ir al banco a pagar, el turno en la Dirección Nacional de Migraciones, tenía que sacar un papel para no pagar el trámite ${ }^{5}$. Y encima tenía a mi hijo chiquito, lo tenía que llevar conmigo a todos lados. Y a la gente del taller donde trabajaba no es que le gustaba que yo faltara para hacer los trámites. (Carina, boliviana, 26 años, Córdoba, 2014)

Como se describe en estos fragmentos, dificultades de tiempo, dinero e información ocasionan el vencimiento de la residencia temporal lo que supone tener que reiniciar la totalidad del circuito burocrático. Quizás lo más sorprendente de los relatos sea la paciencia y persistencia de ir una y otra vez sin la seguridad de poder obtener aquello que se espera. "Hacer esperar", indica Auyero (2013), supone la construcción cotidiana de sujetos que saben que deben ser "pacientes" y que aprenden a serlo en la propia interacción con el Estado. Así lo cuenta Renata:

Sí, ahora donde yo voy y no me atienden, yo digo "no me voy a mover hasta que no me atiendan", más bien yo soy la brava (...) Yo no me muevo. Ahora aprendí que es así, cuando te ven que tú te sientas ahí dicen, "ah, ésta no se va a mover, entonces hay que atenderla", si no, no. Prefiero quedarme medio día y que me atiendan, hasta que me den una respuesta. (Renata, peruana, 44 años, 2018, Córdoba)

Un elemento central de la experiencia de estas mujeres en su vínculo con el Estado es su responsabilidad de los trámites propios, pero también de los de sus hijos/as y de otras personas migrantes que requieren su ayuda. Son ellas las responsables de la gestión de la relación con las instancias estatales, convirtiéndose en otro trabajo absolutamente necesario que recae en sus manos, sus cuerpos y en sus tiempos.

\footnotetext{
5 Se refiere al "certificado de indigencia" que se otorga para eximir del pago de la tasa migratoria a aquellas personas que demuestren (a partir de un relato basado en las carencias materiales de los lugares donde viven) que no cuentan con fondos para hacerlo.
} 


\section{Salud}

El acceso a la salud en Buenos Aires y en Córdoba es universal y está garantizado por el Estado nacional y las instancias locales. El sistema de salud argentino está constituido por tres sectores: el sector público, que se financia a través de las rentas generales y se rige por los principios de universalidad y equidad de la atención; el sector de las obras sociales, que es un sistema de protección de la salud obligatorio para los y las trabajadores en relación de dependencia; y el sector privado cuyas prestaciones son solventadas a través de la contratación de sistemas prepagos o mediante pagos directos de los usuarios (Jelin, 2006).

La mayor parte de nuestras interlocutoras utilizan el sistema público de salud, tanto para su propia atención como para la de sus familias. En general, son experiencias definidas positivamente a partir de la posibilidad del acceso universal al sistema de salud pública que incluso es mencionado como uno de los motivos de permanencia en las ciudades. El único problema que se repite en diferentes testimonios es el tiempo que se requiere entre la solicitud de un turno y la concreción de la consulta o práctica médica. El acceso a la salud de las poblaciones migrantes, como las de otros grupos que dependen del sistema público de salud, demanda de tiempo para poder esperar.

Según datos referenciados en el trabajo de Ballesteros, Freidin y Wilner (2017), los grupos sociales de menores ingresos, menor nivel educativo formal y que cuentan únicamente con cobertura pública, son los que en mayor medida deben esperar más para ser atendidos. De esta manera, no se trata de un "problema de migrantes" sino de la ubicación en el sistema social argentino que ocupan los migrantes, independientemente de su origen social y sus credenciales educativas. Carla (paraguaya, 2018, CABA) lo resume de este modo: "ilo que cuesta de ir al hospital público? Tener que esperar".

Los relatos sobre las largas esperas para obtener los turnos son las más mencionadas al señalar problemáticas en el acceso a la salud. Si bien también las esperas una vez obtenido el turno son largas y tediosas, las primeras se destacan por lo inciertas: nunca se sabe si se va a obtener lo que se fue a buscar. Tal como lo que ocurre con otras dependencias estatales, la incertidumbre es una dimensión central de estas esperas (Auyero, 2013). Como señala Silvia en el fragmento que sigue, se pierde tiempo esperando sin poder acceder al objeto deseado. "Se pierde el tiempo y en vano":

Y, lo más difícil serían los turnos. Es difícil conseguir porque a veces uno va y a las 5 de la mañana, eso varias veces me pasó en salita cuando mi hija, iba a las 5 de la mañana y... Ellos abren a las 8 y media. Tú haces en vano el turno, te dicen "no, hay para doce niños, o sino 10 niños", y entonces ahí pierdes el tiempo y en vano haces la fila. (Silvia, boliviana, 33 años, 2018, CABA) 
Fui al Fernández, pero había que estar, un turno de gastroenterólogo tenía que ser el número 1, y yo estaba a las 5 de la mañana clavada ahí, y luego mis hermanas o me reemplazaban a las 8 porque tenía que trabajar, estar a las 9. Ese esfuerzo lo hacía yo o mi hermana al otro día, fue un esfuerzo descomunal. (Rosa, peruana, 43 años, 2017, CABA)

Las mujeres nos cuentan lo que esperan por un turno para ellas, sus parejas, sus hijos/as, algún familiar dependiente. En estos casos, nuevamente la espera es "cosa de mujeres", tal como ocurre con la gestión de la residencia. La "pobreza de tiempo" descripta en el apartado anterior pareciera no incidir en la feminización de las esperas. No es el exceso de tiempo lo que explica la mayor presencia de mujeres en las colas de las agencias estatales sino el hecho de que sea "su responsabilidad". Son las madres, las hermanas y las esposas quienes van al hospital o la salita, hacen la cola, solicitan el turno, esperan en las salas de espera y van a la consulta. Como bien sugieren Ballesteros, Freidín y Wilner (2017), son las mujeres quienes despejan las principales barreras para acceder a los servicios de salud en Argentina.

Las mujeres migrantes que no pueden ausentarse de sus trabajos para obtener este plus temporal ni pueden pagar el tiempo de otras personas para paliar este déficit, deben desarrollar otras estrategias. A veces, como lo señala Rosa en el fragmento anterior, se turnan entre mujeres para sostener el lugar de la fila. Otras, deben ir a esperar con sus hijos cumpliendo sus otras responsabilidades como cuidadoras no remuneradas.

Entonces me fui a hacer nuevos estudios. Fui a la mañana temprano, con Luisa
-su hija- sin comer porque tenés que ir sin comer y encima a la noche tenés que
comer poco. Estuve esperando como hasta la 1, hasta que una señora (médica o
enfermera) me preguntó qué esperaba, se puso a buscar los estudios y los habían
perdido o no los habían hecho, así que de nuevo me tuvieron que sacar sangre.
Encima yo sin comer, Luisa con hambre, pero no la podía acompañar a ningún lado
ni siquiera al quiosco me sentía muy mal, no tenía nadie que la cuide. Cuando nos
dieron los estudios me dio la diabetes muy alta, así que me tuve que quedar un
rato más en el hospital. Y después me vine para mi casa pero no podía ni caminar
me sentía muy mal. Y tuve que esperar el colectivo, no me alcanzaba para el taxi.
(Liliana, peruana, 38 años, 2013, Córdoba)

Los múltiples tiempos de espera que imponen las agencias estatales para ser atendido representan un obstáculo para acceder a sus servicios (Ballesteros, Freidin, Wilner, 2017). De modo que esperar por otros/as supone la posibilidad de garantizar su acceso a los derechos ofrecidos por el Estado.

Tener salud y acceder a la documentación que posibilite la regularidad migratoria resultan de poder esperar, una práctica ejercida por las mujeres migrantes que se suma a las otras tareas de cuidados diarias de las que son directamente responsables. Esperar, esta ocupación naturalizada, demanda tiempo y presencia física que inevitablemente se quita a otras esferas y que tiene consecuencias en sus trayectorias laborales y familiares. Junto con el resto 
de las ocupaciones de cuidado no remuneradas, los largos viajes y las extensas jornadas de trabajo, el tiempo de espera restringe sus opciones laborales o la posibilidad de realizar otras actividades no remuneradas fuera del ámbito familiar (estudiar, capacitarse, participar en organizaciones culturales y/o políticas y en actividades recreativas, etc.).

\section{Reflexiones finales}

Este artículo se focalizó en el análisis del déficit temporal de las mujeres migrantes que, aun así, son las encargadas principales de esperar por otros/ as. Hemos visto que la espera estructura la vida de las mujeres migrantes en los ámbitos urbanos argentinos, y no solo por su condición migrante o por su pertenencia de clase sino porque son las responsables principales de las esperas familiares. El hecho de esperar por otros/as y la centralidad del "modelo paciente" (Auyero, 2013) en la relación con el Estado supone asumir la responsabilidad del acceso a derechos básicos. De esta manera, esperar por otros/as implica responder a necesidades de las personas que se relacionan con su bienestar corporal y emocional. Como otras prácticas de cuidado, el hecho de que sean las mujeres quienes asuman la tarea de la espera se comprende como una prolongación de la naturaleza femenina y, por lo tanto, como una labor que debe ser realizada en forma gratuita o mal remunerada. Solo se percibe su importancia cuando no es posible que las mujeres esperen.

La necesidad de contar con este tiempo adicional, imprescindible para garantizar el acceso a diferentes derechos, colisiona frecuentemente con los horarios habituales de las jornadas laborales de las mujeres. Hemos señalado la falta de agencia temporal de nuestras entrevistadas: trabajadoras domésticas contratadas por los sectores medios y altos de las ciudades que deben recorrer largos trayectos para llegar a sus lugares de trabajo, y costureras que trabajan bajo la modalidad a destajo, que se traduce en jornadas laborales interminables y sin descanso. El grado de informalidad que estos empleos tienen en el país impide la solicitud formal de licencias o permisos especiales que permitan esperar los tiempos estatales. Las mujeres migrantes dependen de arreglos informales que son percibidos como favores realizados por los empleadores. En pos de ganar algo de tiempo es que emerge el trabajo comunitario desarrollado en los barrios que habitan, en general periféricos y relegados, como una muestra de las posibles estrategias y márgenes de acción que despliegan ante las limitaciones que les impone el contexto social.

El foco puesto en las implicancias de las esperas en la vida cotidiana de las mujeres migrantes permite, en definitiva, reconceptualizar la propia categoría de cuidado a partir de incorporar aquellas relaciones sociales -el tiempo de espera- que resultan centrales para la sostenibilidad de la vida personal y familiar. Se trata de visibilizar las esperas, en tanto -insistimos- 
expresión de relaciones de poder y dominación, como un modo de disputa política de los roles asignados "naturalmente" a las mujeres que van más allá de la falsa dicotomía entre lo productivo y reproductivo, lo público y privado, lo doméstico y extradoméstico. Precisamente, una mirada crítica sobre las esperas permite dar cuenta de los vínculos inquebrantables entre esas esferas que se materializan en las vidas y en los cuerpos de las mujeres migrantes.

\section{Referencias bibliográficas}

AUYERO, Javier. Pacientes del Estado. Buenos Aires: Eudeba, 2013.

BALLESTEROS, Matías; FREIDÍN, Betina; WILNER, Agustín. Esperar para ser atendido. In: PECHENY, Mario; PALUMBO, Mariana (comps.). Esperar y hacer esperar. Buenos Aires: Teseopress, 2017, p. 63-98.

DUHAU, Emilio. La división social del espacio metropolitano. Una propuesta de análisis. Nueva Sociedad, n. 243, p. 79-91, 2013.

ESQUIVEL, Valeria. Trabajadores del cuidado en la Argentina. En el cruce entre el orden laboral y los servicios de cuidado. Revista Internacional del Trabajo, n. 129, p. 529-547, 2010.

GUTIÉRREZ AGUILAR, Raquel; SALAZAR LOHMAN, Huáscar. Reproducción comunitaria de la vida. Pensando la transformación social en el presente. El Apantle. Revista de Estudios Comunitarios, n. 1, p. 15-50, 2015.

HERRERA, Gioconda. Trabajo doméstico, cuidados y familias transnacionales en América Latina: reflexiones sobre un campo en construcción. Amérique Latine Histoire et Mémoire. Les Cahiers ALHIM [En línea], n. 31, 2016. Disponible en: <http://journals.openedition.org/alhim/5430>. Consulta: 01.03.2017.

JELIN, Elizabeth. Salud y Migración Regional. Ciudadanía, discriminación y comunicación intercultural. Buenos Aires: IDES, 2006.

KOBELINSKY, Carolina. Le temps dilaté, l'espace rétréci. Terrain [En ligne], n. 63, 2014. Disponible en: <https://doi.org/10.4000/terrain.15479>. Consulta: 12.04.2019.

MAGLIANO, María José. Los significados de vivir 'múltiples presencias': Mujeres bolivianas en Argentina. Revista Migraciones Internacionales, n. 24, v. 7, p. 165195, 2013.

MAGLIANO, María José; PERSSINOTTI, María Victoria. La periferia autoconstruida: migraciones, informalidad y segregación urbana en Argentina. Revista Eure. Revista Latinoamericana de Estudios Urbanos Regionales, n. 138, v. 46, p. 5-23, 2020.

MAGLIANO, María José; MALLIMACI BARRAL, Ana Inés; BORGEAUDGARCIANDÍA, Natacha; ROSAS, Carolina. Migración y organización social del cuidado en Argentina: un campo de estudio emergente. In: BAENINGER, Rossana et al. (comps.). Migrações Sul-Sul. Campinas: UNICAMP, 2018, p. 741-749. 
MALLIMACI BARRAL, Ana Inés. Experiencias de mujeres migrantes en la Ciudad de Buenos Aires. Migraciones Internacionales. Experiencias desde Argentina. OIM, n. 5, p. 43-61, 2019.

MERA, Gabriela; MARCOS, Mariana. Cartografías migratorias urbanas. Distribución espacial de la población extranjera en la ciudad de Buenos Aires (2010). Geograficando, v. 11, n. 1, 2015. Disponible en: < http://www.geograficando. fahce.unlp.edu.ar/article/view/Geov11n01a04>. Consulta: 03.04.2017.

MERA, Gabriela; VACCOTTI, Luciana. Migración y déficit habitacional en la ciudad de Buenos Aires. Resignificando el 'problema'. Argumentos, n. 15, p. 176-202, 2013.

MEZZADRA, Sandro; NEILSON, Brett. La frontera como método. O la multiplicación del trabajo. Buenos Aires: Tinta Limón, 2016.

MOLINIER, Pascale. Le care à l'épreuve du travail. Vulnérabilités croisées et savoirfaire discrets. In: LAUGIER, Sandra; PAPERMAN, Patricia (dirs.). Le souci des autres. Éthique et politique du care. Paris: Raisons Pratiques, EHESS, 2005, p. 299-316.

PECHENY, Mario; PALUMBO, Mariana (comps.). Esperar y hacer esperar. Buenos Aires: Teseopress, 2017.

ROSAS, Carolina. Mujeres migrantes en el cuidado comunitario. Organización, jerarquizaciones y disputas al sur de Buenos Aires. In: VEGA, Cristina; MARTÍNEZ BUJÁN, Raquel; PAREDES CHACA, Myriam (comps.). Cuidado, comunidad y común. Explorando experiencias, ámbitos y vínculos cooperativos en el sostenimiento de la vida en América Latina y el Sur de Europa. Madrid: Traficantes de Sueños, 2018, p. 201-321.

SCRIBANO, Adrián. Primero hay que saber sufrir...!!!. Hacia una sociología de la 'espera' como mecanismo de soportabilidad social. In: SCRIBANO, Adrián; LISDERO, Pedro (eds.). Sensibilidades en juego: miradas múltiples desde los estudios sociales de los cuerpos y las emociones. Córdoba: CEA-CONICET, 2010, p. 169-192.

VACCOTTI, Luciana. Migraciones e informalidad urbana. Dinámicas contemporáneas de la exclusión y la inclusión en Buenos Aires. EURE, v. 43, n. 129, p. 49-70, 2017.

VEGA, Cristina; GUTIÉRREZ RODRÍGUEZ, Encarnación. Nuevas aproximaciones a la organización social del cuidado. Debates latinoamericanos. ĺconos. Revista de Ciencias Sociales, n. 50, p. 9-26, 2014. 